\title{
Hypoxia-induced VEGF production 'RSUMEs' in pituitary adenomas
}

\author{
Robert C Fowkes and George Vlotides ${ }^{1}$
}

\author{
Endocrine Signalling Group, Royal Veterinary College, University of London, Royal College Street, London NW1 OTU, UK \\ ${ }^{1}$ Department of Internal Medicine II, University-Hospital Munich-Grosshadern, University of Munich, Marchioninistraße 15, 81377 \\ Munich, Germany \\ (Correspondence should be addressed to R C Fowkes; Email: rfowkes@rvc.ac.uk)
}

\begin{abstract}
Angiogenic markers in pituitary adenomas remain enigmatic in terms of their function in tumorigenesis, despite being upregulated by the normal physiological trigger of hypoxia. In this issue of Endocrine-Related Cancer, Shan et al. report that the novel RWD domain containing protein, RWD-containing sumoylation enhancer, is expressed in human pituitary adenomas and plays a pivotal role in regulating the hypoxia-inducible factor $1 \alpha$-vascular endothelial growth factor response to hypoxia.
\end{abstract}

Endocrine-Related Cancer (2012) 19 C1-C5

\section{Introduction}

The anterior pituitary is a highly vascularized gland that acts as a pivotal regulator of the endocrine system. Although pituitary pathologies are quite rare, they make up a significant number of intracranial tumors and as many as one-tenth of the human population exhibit some evidence of pituitary neoplasia at autopsy (so-called incidentalomas). Pituitary tumors are invariably benign, show slow growth, and generally do not proceed to true malignacy with extracranial metastases. Study of human normal and transformed pituitary tissue is challenging due to the anatomic location of the anterior pituitary gland, the lack of human pituitary cell culture cell lines, and the heterogeneity of pituitary cells. Tumors derived from lactotrophs lead to prolactinoma and cause hypogonadism and galactorrhea. Tumors derived from somatotrophs cause acromegaly. Corticotrophderived tumors lead to Cushing's disease, while rare tumors derived from thyrotrophs cause hyperthyroidism. Gonadotroph-derived tumors may produce gonadotrophins (LH or FSH) but are usually clinically non-functioning.

Pituitary tumorigenesis remains poorly understood as a process, although several promising candidate genes have been identified, such as pituitary tumor transforming gene $(P T T G)$, aryl hydrocarbon receptor interacting protein $(A I P)$, and menin $(M E N 1)$, which have been implicated in the development of pituitary tumorigenesis (Yu \& Melmed 2010, Melmed 2011). The lack of genuine marker genes within pituitary tumors has led investigators to focus on alternative angles to improve the understanding of potential mechanisms of pathogenesis. Study of growth factor signaling and dysregulation within the intrapituitary microenvironment, as well as paracrine control of pituitary homeostasis and angiogenesis, may help elucidate unknown aspects of pituitary tumorigenesis.

\section{Angiogenesis and hypoxia in pituitary tumors}

Pathological angiogenesis is a key mechanism involved in tumor growth as well as other disorders associated with inflammation or ischemia. Many endogenous molecules are associated with an increase in angiogenesis, but the most widely investigated is vascular endothelial growth factor (VEGF). While VEGF is critical for the process of vasculogenesis and angiogenesis during development, it is clear that uncontrolled angiogenesis can exacerbate tumor progression, which makes it a tantalizing prospect for both pharmacological and immunological intervention. The biology of VEGF is complicated by the fact that there are several splice variants of the growth factor (A-E) that can each interact with one of the three VEGF-specific receptor tyrosine kinases to 
drive angiogenesis or related processes (Ferrara 2004). The process of angiogenesis is, therefore, under tight control in normal physiological conditions. The major driver for VEGF production is hypoxia, a physiological scenario typically seen in cancer; this lack of oxygen stimulates the expression of hypoxia-inducible factor 1 (HIFl), a transcription factor of the basic helix-loop-helix family, which in turn increases the $V E G F$ expression by the interaction of HIF1 with HIF1-responsive elements within the VEGF promoter.

The normal pituitary is densely vascularized allowing the regulation of pituitary cell growth and hormone secretion by hypothalamic factors, peripheral hormones, and intra-pituitary growth factors. Indeed, multiple intra-pituitary growth factors, such as epidermal growth factor, basic fibroblast growth factor (bFGF), and VEGF, are expressed at high levels within the pituitary and are implicated in pituitary tumorigenesis (Yu \& Melmed 2010).

The role of VEGF in pituitary tumorigenesis is intriguing, given that these tumors are rarely aggressive and would, therefore, appear not to rely on angiogenesis to increase the delivery of nutrients to the tumor. Indeed, the vascularization of pituitary tumors has been shown previously to be less than that of normal anterior pituitary tissue (Turner et al. 2000, Onofri et al. 2006). Despite this, increased angiogenesis is positively correlated with macroprolactinomas (Turner et al. 2000), which suggests that VEGF might be related to tumor size, at least in lactotrophs, as well as to malignant transformation of pituitary adenomas, as highest levels of microvessel density are detected in rare pituitary carcinomas (Vidal et al. 2001). In the absence of a strong correlation between pituitary tumorigenesis in general and angiogenesis (Vidal et al. 2000), the fact that VEGFA is typically over-expressed in most pituitary tumors (Onofri et al. 2006) could also suggest non-angiogenic mechanisms of action.

\section{Pituitary tumor HIF1 $\alpha-$ VEGF pathway}

The absence of correlation between HIF $1 \alpha$ and VEGF mRNA expression in pituitary tumors reported by Kim et al. (2005) and the observed anti-apoptotic actions by HIF $1 \alpha$ in a human pituitary adenoma cell line (HP-75; Yoshida et al. 2006) could suggest a VEGF-independent HIF $1 \alpha$-mediated regulation of pituitary tumor growth. Such findings are interesting but require further validation with established pituitary tumor cell lines and primary cultures.

Previous studies identified a small RWD domain containing a protein called RWD-containing sumoylation enhancer (RSUME; Carbia-Nagashima et al. 2007). RSUME was identified following a screen of gp130 over-expressing GH3 somatolactotroph cells that typically generate aggressive and highly vascularized tumors when injected into nude mice (Castro et al. 2003). The expression of RSUME was linked to hypoxia and associated with a concomitant increase in HIF $1 \alpha$ expression (Carbia-Nagashima et al. 2007). In a new article, published in this issue of EndocrineRelated Cancer, Shan et al. (2012) elaborate further on the role of RSUME in pituitary tumorigenesis, by demonstrating that it lies upstream of $H I F l \alpha$ and VEGFA expression. They show that RSUME appears to be upregulated in most pituitary adenomas, regardless of the cellular origin, and has a strong positive correlation with $H I F 1 \alpha$ expression (which itself is strongly correlated with $V E G F$ expression). Further in vitro studies demonstrated that hypoxia or treatment with $\mathrm{CoCl}_{2}$ increased RSUME and HIFl $\alpha$ expression and nuclear translocation, as well as VEGFA production in established anterior pituitary cell lines (AtT-20 corticotrophs and TtT/GF folliculostellate cells (FS)) and primary cultures of human pituitary adenomas. Through an intricate series of molecular manipulations in both pituitary cell lines and primary cultures, they confirmed that silencing of RSUME results in reduced HIFl $\alpha$ expression, VEGF secretion, and a diminished response to hypoxia. A proposed mechanism of action for RSUME is shown in Fig. 1.

In support of the recent report by Luque et al. (2011) that demonstrated inhibitory effects of anti-VEGF strategies in experimental dopamine-resistant prolactinomas, these findings suggest an important role of VEGF signaling in pituitary tumor growth. Pituitary tumors may have a lower microvessel density compared with the highly vascularized normal pituitary gland, but hypoxic conditions within the tumor may still activate the RSUME-HIF1 $\alpha$-VEGF pathway leading to increased vascularization or more ordered microvascular geometry in order to sustain tumor growth. Pituitary tumors require an intact and sustainable vessel system for nutrient supply, also demonstrated by the fact that pituitary tumor hormone secretion often retains intact trophic control (dopaminergic suppression of prolactin secretion in prolactinomas and dexamethasone-mediated suppression of ACTH secretion in Cushing's disease). Despite the controversial data on vessel density in pituitary tumors, inhibition of the RSUME-HIF1 $\alpha-$ VEGF activity could alter the microvascular structure supporting pituitary adenomas with growth mediators.

In parallel to changes in the vascular supply of the tumor, VEGF secretion may exhibit direct proliferative 


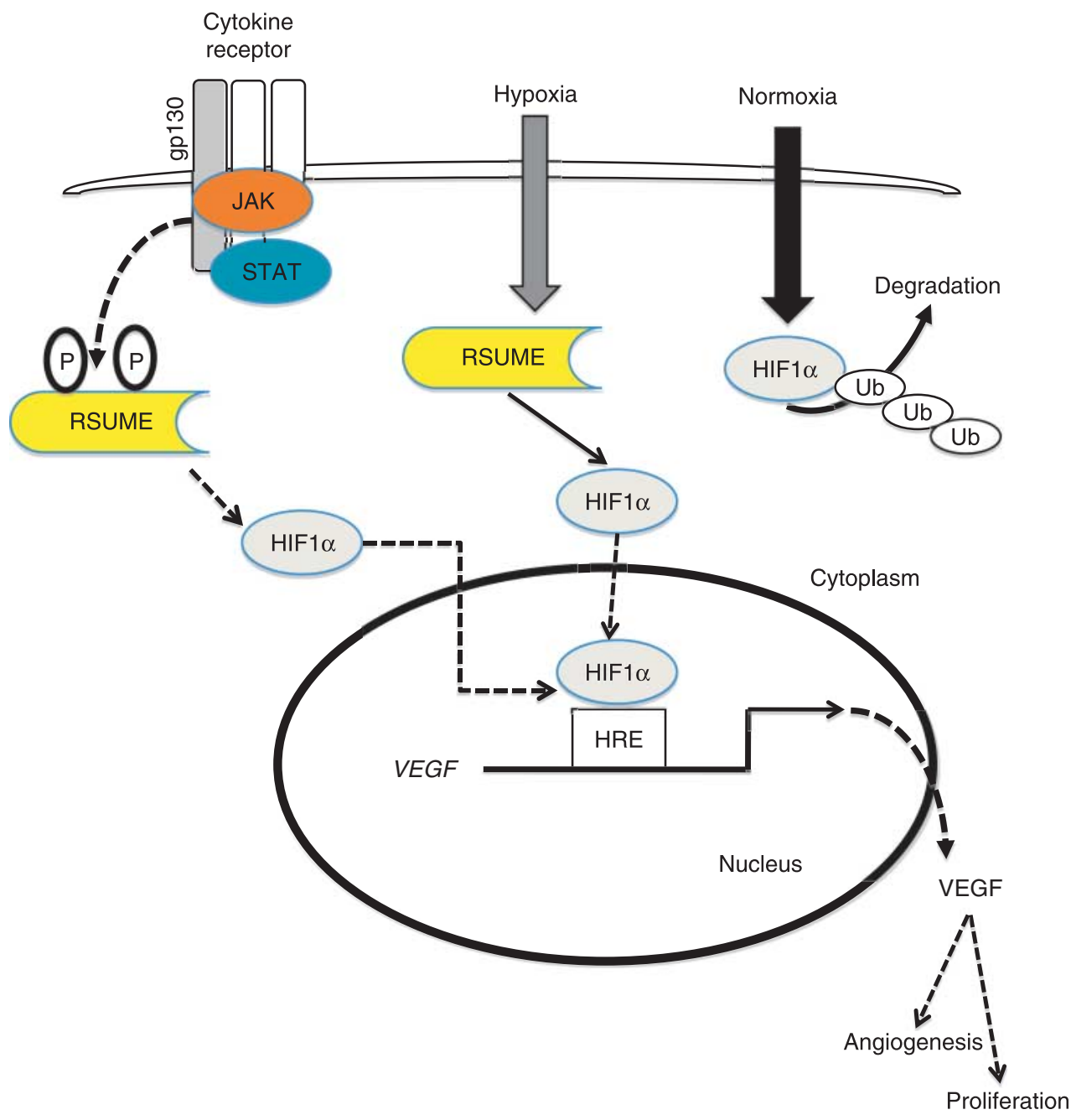

Figure 1 Possible RSUME-HIF1 $\alpha$-VEGF pathway in pituitary adenomas. RSUME, an RWD-domain containing protein with homology to ubiquitin conjugating enzyme domains, contains at least two putative JAK-STAT-sensitive tyrosine phosphorylation sites within the predicted protein sequence. Activation of these pathways, either through elevated cytokine signaling during inflammation, or during hypoxic conditions, could lead to increased RSUME expression or activity, resulting in enhanced HIF1 $\alpha$ expression/stabilisation and subsequent transcriptional activation of the VEGF gene through HIF1 $\alpha$-response elements (HRE). Secretion of VEGF could then lead to autocrine/paracrine effects on cell proliferation or stimulation of angiogenesis. $(P$, phosphorylation site; Ub, ubiquitin). Phosphorylation site prediction from Kinasephos (http://kinasephos.mbc.nctu.edu.tw/index.php).

effects on pituitary tumor cells. Pituitary tumor cells express VEGF receptors such as KDR/Flk-1 (McCabe et al. 2002) and VEGF-mediated induction of cell proliferation has been described in a pituitary tumor cell line (Onofri et al. 2006). On the other hand, VEGF may prolong pituitary tumor cell survival through induction of anti-apoptotic signaling. Thus, inhibition of direct VEGF effects on pituitary tumor cells could suppress tumor growth independently of its effects on vessel formation.

In addition to intra-tumoral VEGF secretion as an autocrine stimulus, pituitary folliculostellate cells appear to express the RSUME-HIF1 $\alpha$ machinery and are a rich source of intra-pituitary VEGF. These enigmatic cells constitute the major group of nonhormonal pituitary cells comprising approximately $5-10 \%$ of the anterior pituitary cell mass. With their characteristic stellate shape and long cytoplasmic processes, they form an intra-pituitary cell network coupled by gap junctions capable of transmitting intercellular signals in the gland and are associated with increased cell proliferation and hormone secretion in pituitary adenomas (Gloddek et al. 1999, Renner et al. 2009). In this article, Shan et al. (2012) show that folliculostellate TtT-GF cells express RSUME suggesting that folliculostellate cells are exquisitely equipped to rapidly respond to local changes in oxygen concentrations to elicit RSUME-dependent production 
of VEGF. Intriguingly, FS cells are also a major site of cytokine production and action in the pituitary; given the original description of RSUME from gp130 overexpression GH3 cells (Castro et al. 2003, CarbiaNagashima et al. 2007), the link between cytokine signaling and RSUME activity strengthens the potential role for FS cells in mediating the RSUME response to hypoxia. Thus, hypoxia-mediated regulation of FS cell-derived VEGF secretion in the periphery of the tumors could sustain tumor growth in a paracrine manner.

\section{Summary}

In search of mechanisms elucidating the role of growth factor signaling in pituitary tumorigenesis, Shan et al. (2012) examined the role of the recently cloned RWD domain containing protein RSUME in $\mathrm{HIF} \alpha$-induced VEGF production in pituitary tumor cells. They demonstrate upregulated RSUME expression in pituitary adenomas and hypoxia-induced activation of the RSUME/HIF1/VEGF pathway, as well as RSUME siRNA-mediated suppression of these effects. Given the controversy on the role of angiogenesis in pituitary tumors, these findings expand our understanding of angiogenic mechanisms involved in pituitary tumorigenesis. Further studies are needed to examine the effects of RSUME-HIF1 $\alpha-$ VEGF pathway blockade on autocrine and paracrine induction pathways of pituitary tumor angiogenesis and cell proliferation and, indeed, within other endocrine tumors.

\section{Declaration of interest}

The authors declare that there is no conflict of interest that could be perceived as prejudicing the impartiality of the research reported.

\section{Funding}

This research did not receive any specific grant from any funding agency in the public, commercial or not-for-profit sector.

\section{References}

Carbia-Nagashima A, Gerez J, Perez-Castro C, Paez-Pereda M, Silberstein S, Stalla GK, Holsboer F \& Arzt E 2007 RSUME, a small RWD-containing protein, enhances SUMO conjugation and stabilizes HIF-1alpha during hypoxia. Cell 131 309-323. (doi:10.1016/j.cell.2007.07. 044)

Castro CP, Giacomini D, Nagashima AC, Onofri C, Graciarena M, Kobayashi K, Páez-Pereda M, Renner U, Stalla GK \& Arzt E 2003 Reduced expression of the cytokine transducer gp130 inhibits hormone secretion, cell growth, and tumor development of pituitary lactosomatotrophic GH3 cells. Endocrinology 144 693-700. (doi:10.1210/en.2002-220891)

Ferrara N 2004 Vascular endothelial growth factor: basic science and clinical progress. Endocrine Reviews 25 581-611. (doi:10.1210/er.2003-0027)

Gloddek J, Pagotto U, Paez Pereda M, Arzt E, Stalla GK \& Renner U 1999 Pituitary adenylate cyclase-activating polypeptide, interleukin-6 and glucocorticoids regulate the release of vascular endothelial growth factor in pituitary folliculostellate cells. Journal of Endocrinology 160 483-490. (doi:10.1677/joe.0.1600483)

Kim K, Yoshida D \& Teramoto A 2005 Expression of hypoxia-inducible factor 1alpha and vascular endothelial growth factor in pituitary adenomas. Endocrine Pathology 16 115-121. (doi:10.1385/EP:16:2:115)

Luque GM, Perez-Millán MI, Ornstein AM, Cristina C \& Becu-Villalobos D 2011 Inhibitory effects of antivascular endothelial growth factor strategies in experimental dopamine-resistant prolactinomas. Journal of Pharmacology and Experimental Therapeutics 337 766-774. (doi:10.1124/jpet.110.177790)

McCabe CJ, Boelaert K, Tannahill LA, Heaney AP, Stratford AL, Khaira JS, Hussain S, Sheppard MC, Franklyn JA \& Gittoes NJ 2002 Vascular endothelial growth factor, its receptor KDR/Flk-1, and pituitary tumor transforming gene in pituitary tumors. Journal of Clinical Endocrinology and Metabolism 87 4238-4244. (doi:10.1210/ jc.2002-020309)

Melmed S 2011 Pathogenesis of pituitary tumors. Nature Reviews. Endocrinology 7 257-266. (doi:10.1038/nrendo. 2011.40)

Onofri C, Theodoropoulou M, Losa M, Uhl E, Lange M, Arzt E, Stalla GK \& Renner U 2006 Localization of vascular endothelial growth factor (VEGF) receptors in normal and adenomatous pituitaries: detection of a non-endothelial function of VEGF in pituitary tumours. Journal of Endocrinology 191 249-261. (doi:10.1677/joe.1.06992)

Renner U, De Santana EC, Gerez J, Fröhlich B, Haedo M, Pereda MP, Onofri C, Stalla GK \& Arzt E 2009 Intrapituitary expression and regulation of the gp130 cytokine interleukin-6 and its implication in pituitary physiology and pathophysiology. Annals of the New York Academy of Sciences 1153 89-97. (doi:10.1111/j.17496632.2008.03970.x)

Shan B, Gerez J, Haedo M, Fuertes M, Theodoropoulou M, Buchfelder M, Losa M, Stalla GK, Arzt E \& Renner U 2012 RSUME is implicated in HIF-1-induced VEGF-A production in pituitary tumour cells. Endocrine-Related Cancer 19 13-27. (doi:10.1530/ERC-11-0211)

Turner HE, Nagy Z, Gatter KC, Esiri MM, Harris AL \& Wass JA 2000 Angiogenesis in pituitary adenomas and the normal pituitary gland. Journal of Clinical Endocrinology and Metabolism 85 1159-1162. (doi:10. 1210/jc.85.3.1159) 
Vidal S, Scheithauer BW \& Kovacs K 2000 Vascularity in nontumorous human pituitaries and incidental microadenomas: a morphometric study. Endocrine Pathology 11 215-227. (doi:10.1385/EP:11: 3:215)

Vidal S, Kovacs K, Horvath E, Scheithauer BW, Kuroki T \& Lloyd RV 2001 Microvessel density in pituitary adenomas and carcinomas. Virchows Archiv: an International Journal of Pathology 438 595-602. (doi:10.1007/ s004280000373)

Yoshida D, Kim K, Noha M \& Teramoto A 2006 Antiapoptotic action by hypoxia inducible factor 1-alpha in human pituitary adenoma cell line, HP-75 in hypoxic condition. Journal of Neuro-Oncology 78 217-225. (doi:10.1007/s11060-005-9017-9)

Yu R \& Melmed S 2010 Pathogenesis of pituitary tumors. Progress in Brain Research 182 207-227. (doi:10.1016/ S0079-6123(10)82009-6)

Received in final form 19 September 2011 Accepted 18 October 2011 Made available online as an Accepted Preprint 18 October 2011 